\title{
Management of Radical Mastectomy under Sole Thoracic Paravertebral Block in a 92 years Old Patient with Cardio- Pulmonary Dysfunction
}

\author{
Kalpana Kulkarni*, Prachi Dubey, Madhurima Sinha Ray \\ Department of Anaesthesiology, DY Patil Medical College, Kolhapur, Maharashtra, India \\ *Corresponding Author: Kalpana Kulkarni, Department of Anaesthesiology, DY Patil Medical College, \\ Kolhapur, Maharastra, India, E-mail:drrmk@rediffmail.com
}

\begin{abstract}
Radical mastectomy is routinely performed under general anaesthesia, but geriatric patients with compromised cardio-pulmonary function are at increased risk of morbidity and mortality. We report successful perioperative management of radical mastectomy with sole paravertebral block in a 92 years old female with compromised cardio-pulmonary function and kyphoscoliotic spine. Single needle thoracic paravertebral block was given at T4 level using tuohy's needle and 18 guage epidural catheter was inserted $3 \mathrm{~cm}$ into the paravertebral space on right side. Ropivacaine $0.5 \%, 15 \mathrm{ml}(75 \mathrm{mg}, 1.5 / \mathrm{kg})$ with fentanyl $25 \mathrm{mcg}$ $(0.5 \mathrm{mcg} / \mathrm{kg})$ was injected through the catheter. There was good hemodynamic stability, surgical field and postoperative analgesia.
\end{abstract}

Thus sole paravertebral block as an anaesthetic technique is a good option for unilateral surgical anaesthesia for radical mastectomy with minimal hemodynamic changes especially in high risk patients.

Keywords: Paravertebral Block, Ropivacaine, Radical mastectomy

\section{INTRODUCTION}

Regional anaesthesia has distinct advantages over general anaesthesia (GA) specially in cancer breast surgeries like decreased incidence of intraoperative hemodynamic alterations, postoperative nausea/vomiting, shoulder/arm pain ultimately resulting in early mobilization and discharge from the hospital. Thoracic paravertebral block (TPVB) is well reported as an alternative technique for breast surgeries which provides unilateral anaesthesia with hemodynamic stability and postoperative pain relief [1]. Thoracic paravertebral space contains dorsal and ventral rami of spinal nerves, sympathetic chain where injection of local anaesthetic is made that produces unilateral sympathetic, sensory and motor blockade [2,3]. We conducted a study on sole TPVB for radical breast surgeries in 25 ASA grade I-III patients and found it is very safe and useful method [4]. We intend to report a recent high risk case of 92 years old lady with compromised cardiopulmonary function who underwent radical mastectomy under sole TPVB successfully.

\section{CASE REPORT}

A 92 years old female presented with a hard lump of size $4 \times 3 \times 1 \mathrm{~cm}$. Fine needle aspiration cytology revealed intraductal carcinoma so she was scheduled for radical mastectomy. She was a known case of chronic obstructive lung disease stabilized on oral theophylline. She was havingNYHA class III dyspnoea, heart rate (HR) of $110 / \mathrm{min}$, respiratory rate (RR) of $28 /$ min and oxygen saturation $(\mathrm{SpO} 2)$ on room air was $94 \%$ in lying down position and $96 \%$ in sitting position. On auscultation fine crepts and ejection systolic murmur was present in aortic area. Spine was kyphoscoliotic (Figure 1) 2DECHO revealed mild AS, moderate pulmonary hypertension (PASP of $45 \mathrm{mmHg}$ ) and diastolic dysfunction whereas PFT suggestive of severe obstructive lung disease.FEV1 was 1.2lit (44.6 of $\%$ predicted), FVC 3.86 (74.9 of \% predicted) and FEV1/FVC of 0.45 . Following optimization with bronchodilators and antibiotics high risk 
informed consent with permission for the display of photographs for publication purpose was taken. Monitoring started for HR, blood pressure (BP) and $\mathrm{SpO}$ 2. Premedicated with Inj.hydrocortisone $100 \mathrm{mg}$ and theophylline $100 \mathrm{mg}$ along with IV infusion of ringer's lactate. Oxygen supplementation with 4 litres of flow with the ventimask was provided throughout the procedure and postoperatively for 4 hours. In sitting position under asceptic precautions thoracic paravertebral space identified on right side at T4 level with $18 \mathrm{G}$ epidural needle using loss of resistance technique and the catheter passed $4 \mathrm{~cm}$ inside the paravertebral space. Figure-2 Patient was given supine position and then Inj. ropivacaine $0.5 \%$, $75 \mathrm{mg}(15 \mathrm{ml}, 1.5 \mathrm{mg} / \mathrm{kg})$ with fentanyl $25 \mathrm{mcg}$ $(0.5 \mathrm{mcg} / \mathrm{kg})$ injected through the catheter placed into the paravertebral space. There was good hemodynamic stability with HR $80-100 / \mathrm{min}$, systolic BP120-130mm of $\mathrm{Hg}, \mathrm{SpO} 2$ of 96-98\%. Top up doses with $5 \mathrm{ml} 0.5 \%$ ropivacaine were given one hourly or whenever patient complained of pain/ discomfort. Surgery lasted for eighty minutes and intraoperative blood loss was $200 \mathrm{ml}$ approximately. Patient received analgesic top up dose of $16 \mathrm{mg}(8 \mathrm{ml})$ of $0.2 \%$ ropivacaine in the recovery room, observed for two hours, shifted to the intensive care unit for one day period and lare to the wards. She was observed for $\mathrm{HR}, \mathrm{BP}, \mathrm{RR}, \mathrm{SpO} 2$, VAS score for pain, urine output and for signs of respiratory discomfort. Post-operative analgesia was provided through the paravertebral catheter for two days with $16 \mathrm{mg}(8 \mathrm{ml})$ of $0.2 \%$ ropivacaine every six hours or when VAS score >3. The patient was discharged on 5th postoperative day.

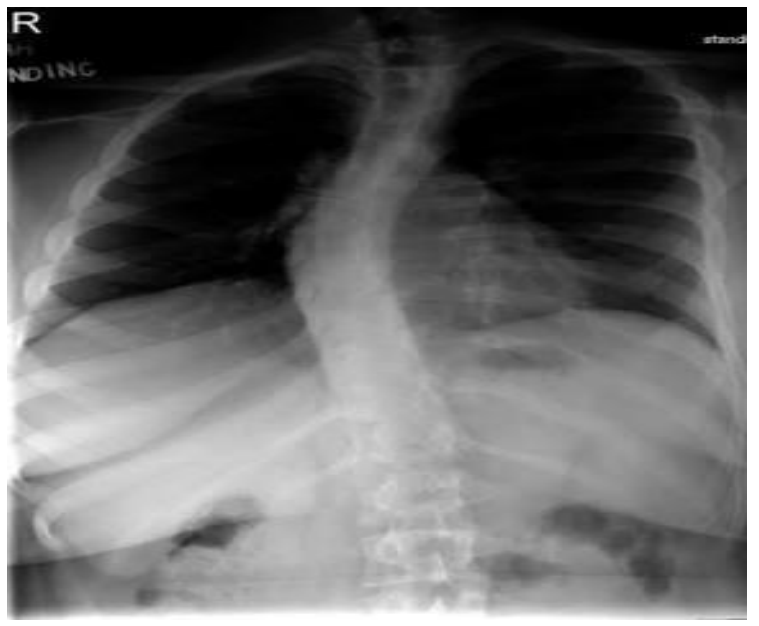

Figure1. X-ray chest showing kyphoscoliosis of thoracic spine.

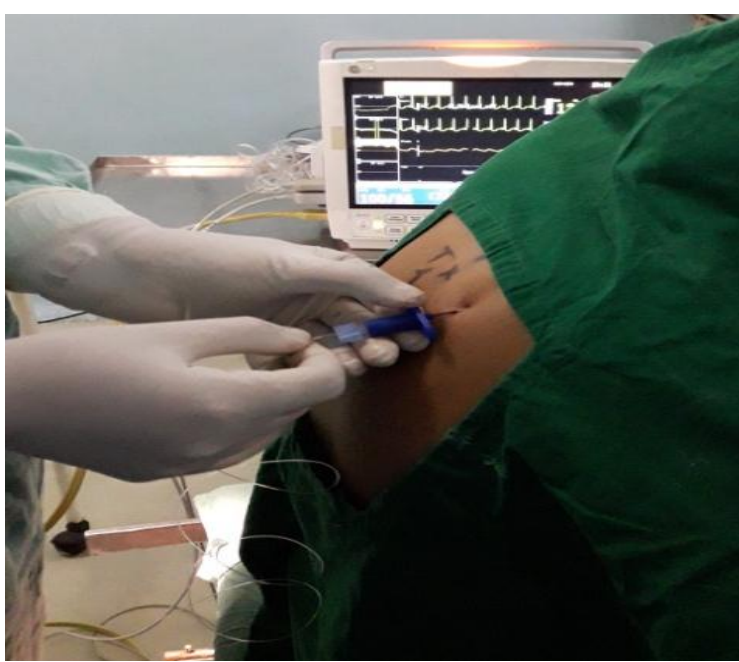

Figure2. Epidural catheter insertion into the thoracic paravertebral space

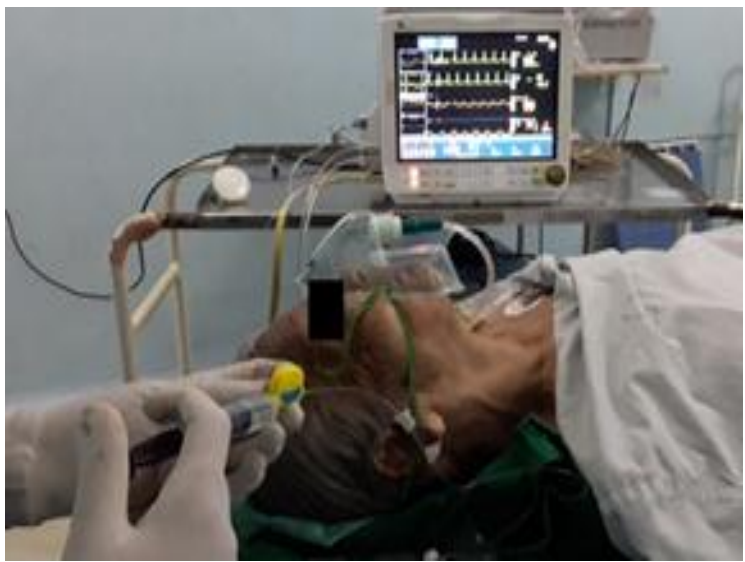

Figure3. Postoperative analgesia delivered through the catheter.

\section{DISCUSSION}

TPVB was introduced in 1905 by Hugo Sellheim but for many years it was used mainly for acute and chronic pain management arising from fracture ribs, herpetic neuralgia, plurasy and post thoracotomy pain.The anaesthetic use has been explored in recent years for shoulder and chest wall surgeries and observed its safety and efficacy for female mastectomies [5]. We followed the technique described by Pusch et al. where local anaesthetic like bupivacaine or ropivacaine injected through single needle in thoracic paravertebral space at $\mathrm{T}$ 3-6 level to produce surgical anaesthesia in 6-8 thoracic dermatomes and observed satisfactory surgical anaesthesia for cancer breast surgeries[6]. Use of ropivacaine for its better safety profile is well documented and addition of dextmeditomidine produces anxiolysis, potentiates analgesia and provides good hemodynamic stability $[7,8]$. Currently use of ultrasonography for identification and accurate placement of catheter 
in the paravertebral space is increasing to minimize the risk of intravascular injection and toxicity, pleural puncture or pneumothorax [9].Coveney $\mathrm{E}$ et al. reported retrospective analysis of 156 patients operated for cancer breast surgery under thoracic paravertebral block. They found success rate of $91 \%$ without need of supplementation with GA and observed minimal rate of complications of $2.6 \%$. Complications reported in their study are bilateral or epidural spread of local anaesthetic drug, local anaesthetic toxicity reaction and one patient had pneumothorax that resolved spontaneously [10]. Exadaktylos in his retrospective study on 129 cases of breast cancer surgery under TPVB found significant reduction in tumour recurrence and spread because of the reduced stress response and improved immune function [11].

In our patient Inj. ropivacaine $0.5 \%, 75 \mathrm{mg}$ $(15 \mathrm{ml}, \quad 1.5 \mathrm{mg} / \mathrm{kg}) \quad$ with fentanyl $25 \mathrm{mcg}$ $(0.5 \mathrm{mcg} / \mathrm{kg})$ injected through the catheter placed into the paravertebral space. The patient was sedated but arousable, satisfactory analgesia with surgical anesthesia and hemodynamic stability observed. This technique avoids the complications of GA as well as side effects and complications of neuroaxial method of anaesthesia i.e. thoracic epidural anaesthesia producing bilateral effectsand hemodynamic instability, also poses risk of other neurological complications. Our patient did not require any supplementation of general anaesthetic or analgesics intraoperatively. Postoperative analgesia was maintained with ropivacaine $0.2 \%$ $16 \mathrm{mg}(8 \mathrm{ml})$ six hourly through the paravertebral catheter for 48 hours. There was no incidence of respiratory discomfort, desaturation suggestive of pneumothorax or hemodynamic instability in the postoperative period.

\section{CONCLUSION}

TPVB provided adequate anaesthesia, cardiopulmonary stability, analgesia and satisfaction to the patient. It proved to be an excellent anaesthesia technique for radical mastectomy in our geriatric patient with compromised cardiopulmonary function.

\section{ACKNOWLEDGEMENT}

We are thankful to department of Oncosurgery, D.Y. Patil Hospital for their cooperation during conduct and publication of this case.

\section{REFERENCES}

[1] Pusch F, Freitag H, Weinstabl C, Obwegeser R, Huber E, Wildling E. Single-injection paravertebral block compared to general anaesthesia in breast surgery. Acta Ana esthesiolSc and 1999; 43: 770-4.

[2] Bonica J. Local Anesthesia and regional blocks. 2nd ed. New York: Churchill Livingstone 1989; 14-20.

[3] Karmakar MK. Thoracic paravertebral block. Anesthesiology 2001; 95:771-80.

[4] Kulkarni KR. Single Needle Thoracic Paravertebral Block with Ropivacaine and Dexmeditomidine for Radical Mastectomy: Experience in 25 Cases. International Journal of Anaesthesiology \& Pain Medicine. 2017;1: 4

[5] Schnabel A, Reichl SU, Kranke P, PogatzkiZahn, Zahn PK. Efficacy and safety of paravertebral blocks in breast surgery: A meta analysis of randomized controlled trials. BJA 2010; 105: 842-852.

[6] Pusch F, Freitag H, Weinstabl C. Singleinjection paravertebral block compared to general anaesthesia in breast surgery. Acta AnaesthesiolSc and 1999; 43: 770-804.

[7] Yoshida T, Fujiwara T, Farutani K, Ohashi N, Baba H. Effects of ropivacaine concentration on the spread of sensory block produced by continuous thoracic paravertebral block: a prospective, randomised, controlled, doubleblind study. Anaesthesia 2014; 69: 231-239.

[8] Mohamed SA, Fares KM, Mohamed AA, Alieldin NH. Dexmedetomidine as an Adjunctive Analgesic with Bupivacaine in Paravertebral Analgesia for Breast Cancer Surgery. Pain Physician 2014; 17: E589-E598.

[9] Luyet C, Herrmann G, Ross S, Vogt A, Greif $\mathrm{R}$, Moriggl Bet al. Ultrasound-guided thoracic paravertebral puncture and placement of catheters in human cadavers: where docatheters go? Br J Anaesth 2011; 106:246-54.

Citation: Kalpana Kulkarni, Prachi Dubey, Madhurima Sinha Ray. Management of Radical Mastectomy under Sole Thoracic Paravertebral Block in a 92 years Old Patient with Cardio-Pulmonary Dysfunction. ARC Journal of Anesthesiology. 2017;2(1):1-3. DOI: dx.doi.org/10.20431/2455-9792.0201001.

Copyright: () 2017 Authors. This is an open-access article distributed under the terms of the Creative Commons Attribution License, which permits unrestricted use, distribution, and reproduction in any medium, provided the original author and source are credited. 